\title{
Cost-effectiveness of audiometric screening of first-year preparatory pupils in Dhofar region, Oman
}

\author{
T. Aasham, ${ }^{1}$ R. Khandekar, ${ }^{2}$ M. Khabori ${ }^{3}$ and S.A. Helmi ${ }^{4}$
}

مردودية تحريّي القياسات السمعية لطالب السنة الأولى من المرحلة الإعدادية في منطقة ظُفار في سلطنة

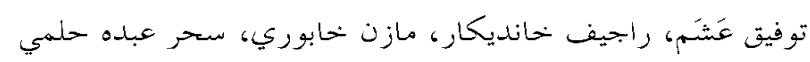

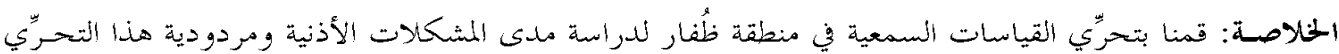

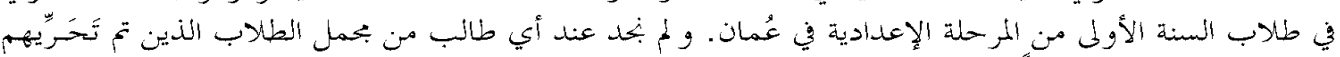

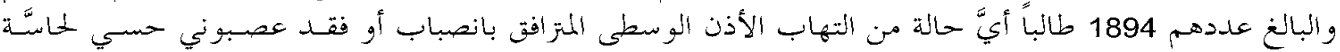

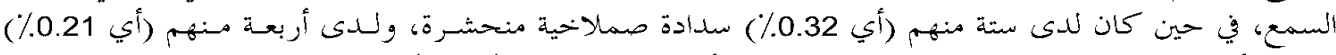

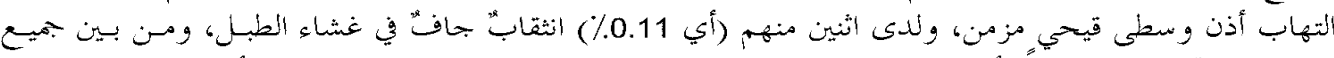

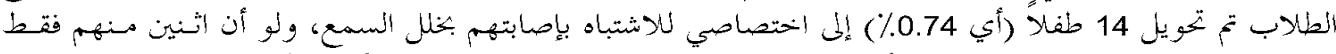

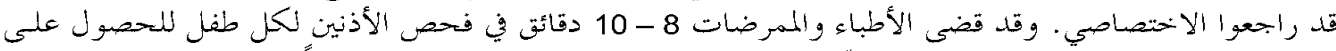

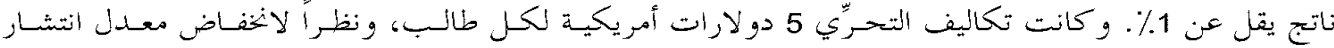

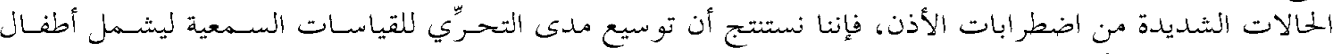

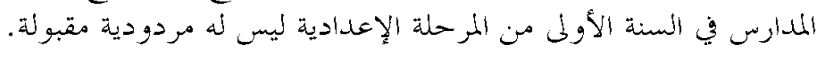

ABSTRACT Audiometric screening was conducted in Dhofar region to study the magnitude of ear problems and cost-effectiveness of screening first-year preparatory-school children in Oman. None of the 1894 pupils had otitis media with effusion or sensory neuronal hearing loss. Six children $(0.32 \%)$ had impacted wax, 4 $(0.21 \%)$ chronic suppurative otitis media and $2(0.11 \%)$ dry perforation of eardrum. In all, 14 children $(0.74 \%)$ with suspected hearing impairment were referred to a specialist but only 2 attended. Physicians and nurses spent 8-10 minutes for ear examination per child for a yield of less than $1 \%$. The screening expenditure was US\$ 5 per pupil. As the prevalence of serious ear conditions was low, we conclude that expanding the audiometric screening of schoolchildren to first-year preparatory pupils is not cost-effective.

\begin{abstract}
Rapport coût-efficacité du dépistage audiométrique chez les élèves de première année du secondaire dans la région de Dhofar (Oman)

RESUME Un dépistage audiométrique a été réalisé dans la région de Dhofar pour étudier l'ampleur des problèmes d'audition et le rapport coût-efficacité du dépistage des élèves de première année du cycle secondaire à Oman. Aucun des 1894 élèves n'avait d'otite moyenne avec épanchement ou de surdité neurosensorielle. Six enfants $(0,32 \%)$ avaient un bouchon de cérumen, quatre enfants $(0,21 \%)$ avaient une otite moyenne suppurée chronique et deux enfants $(0,11 \%)$ une perforation tympanique sèche. En tout, 14 enfants $(0,74 \%)$ suspects de déficience auditive ont été orientés vers un spécialiste mais seuls deux ont consulté. Les médecins et les infirmières ont consacré 8 à 10 minutes par enfant à l'examen auditif pour un rendement de moins de $1 \%$. Les dépenses encourues pour le dépistage s'élevaient à USD 5 par élève. La prévalence des troubles auditifs graves étant faible, nous concluons que l'extension du dépistage audiométrique aux élèves de la première année du secondaire n'est pas rentable.
\end{abstract}

${ }^{1}$ School Health Services, Ministry of Health, Dhofar Region, Oman.

${ }^{2}$ Eye and Ear Health Care Programme; ${ }^{4}$ School Health Services, Directorate General of Health Services;

${ }^{3}$ Ear, Nose and Throat Services, Ministry of Health, Muscat, Oman.

Received: 29/07/03; accepted: 01/09/03

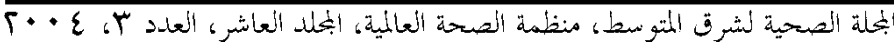




\section{Introduction}

Audiometric screening of first-year primary-school children has been a part of the school health programme in Oman since 1993. The programme aimed to standardize and improve the coverage of screening in the early years [1]. However, a community-based survey conducted in 1996 in Oman found a high prevalence of ear diseases and hearing impairment in children aged over 6 years [2]. Hence, expansion of the service to include universal hearing screening of first-year preparatory-school children was proposed [3].

Any expansion of auditory screening services would divert local physicians to the schools and thus compromise the services at local health centres in the mornings when there is peak demand from patients. Thus it was essential to review the impact of the proposed initiative with a pilot programme in a limited area.

Dhofar region was selected for the pilot study due to its distance from secondary ear care facilities and the availability of sufficient audiometers. Dhofar is the southernmost region of Oman and has a population of $158910,102146(65 \%)$ of whom reside in Salalah wilaya in the coastal plains. The remaining 7 wilayat with a population of 56500 are in mountain and desert terrains with a low population density. The scheme was piloted in the 7 wilayat, except Salalah (the only wilaya with a secondary ear care facility).

Trained physicians and facilities for primary ear care are available at 31 primary health centres in Dhofar region. These wilayat also have 35 preparatory schools accessible to all children and education is provided to them free of charge [4]. Ten doctors of primary heath centres visit schools in their catchment area and conduct various health activities, mainly immunization, screening for early detection and management of health problems and providing first aid to the pupils.

We report here the results of the pilot programme to measure the frequency of ear problems in first-year preparatory pupils and correlate these to the cost of such efforts. The aim was to review of the costeffectiveness of screening and make recommendations for future programmes of auditory screening in Oman.

\section{Methods}

\section{Sample}

This was a school-based cross-sectional analytical study. The study population was first-year preparatory pupils in the selected schools of 8 wilayat. The assumed prevalence of ear problems in this population was $1 \%$. To achieve $95 \%$ confidence interval and $90 \%$ power of the study in a population of 5000 pupils in 3 academic years in all wilayat other than Salalah, we needed a random selection of 882 pupils. As schools were the units for the pupil selection, clustering could affect the sampling. To compensate for this effect, the sample was multiplied by a factor of 2 . To adjust for the loss of data, the sample was enlarged by $10 \%$. Thus, a minimum sample of 1940 was to be enrolled.

\section{Data collection}

Ten physicians were the study investigators. They were trained in primary ear care by an ear, nose and throat (ENT) specialist. Calibrated battery-operated micro-audiometers were used for the hearing screening. An otoscope and ear speculum were used for ear examinations. Pupils were called to the school nursing station in batches of 5 and the physician explained the screening procedures to them. Cuffed headphones were placed properly and sound signals for different frequencies and amplitude were

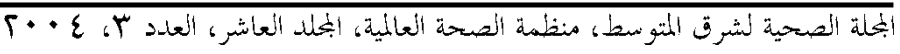


demonstrated. The audiometer was placed behind the child so that he/she could not see its operation. The inputs were given randomly in either ear and the pupil responded by raising a hand if he/she could hear the sound stimulus. For 1, 2 and $4 \mathrm{kHz}$ frequencies, sound signals of $25 \mathrm{~dB}$ and 35 $\mathrm{dB}$ amplitudes were used. In case of nonresponse, the test was repeated after 2 weeks. The observations were charted on a graph in the school health logbook.

The pupils' ears were examined and they were asked about any history of ear disease in the past and visits to the primary health centre for ear problems. If the ear had semi-soft wax, it was removed and then the eardrum was re-examined. If wax was impacted, it was treated with sodium bicarbonate in glycerol ear drops. Pupils with hearing impairment and suspected pathology of the middle ear were referred to an ENT specialist. The physician noted the time required for the audiometry and ear examination in each school.

In children with hearing impairment, the school principal contacted the parents, explained about the possible ear problem and advised them to consult the ENT specialist at Salalah Hospital as soon as possible. After 2 months, compliance with attendance at the ENT specialist and feedback from the consultation were reviewed.

Information on visits by the study children to primary health centres in the last 6 months of the screening was gathered by conducting interviews with the children. Hence recall bias affecting this data cannot be ruled out.

\section{Ethical considerations}

The consent of local and regional health and school authorities was obtained to undertake this study. The pupils found to have ear problems were offered care free of charge. The outcomes of the study were used to improve the ear care of the school pupils and guidelines were distributed to the regional and national ear health care staff.

\section{Costs}

Based on the number of children and the time for each examination, the unit time per child for ear screening of first-year preparatory-school children was calculated. The yield of hearing screening was defined as the proportion of children with hearing impairment and ear diseases to total children examined. The salaries of the physician and the school nurse were calculated per unit time per child. The unit cost of the hearing screening was defined as the cost of the manpower involved as a fraction of the capital cost of the equipment and disposables used for screening per pupil. The indirect costs of diagnosis and care of the child with ear problems were not included.

\section{Analysis}

The data from the screening sessions were collected from the school health logbook using a pre-tested data collection form. The Microsoft XL spreadsheet was used to record the data of all pupils. The data was checked for inconsistencies and analysed using univariate methods. To validate the results, $95 \%$ confidence intervals of the proportions of children with hearing problems were calculated.

\section{Results}

A total of 1894 children were tested over 3 school years $(37 \%$ of the study population). The number of first-year preparatory pupils in the study area by sex is compared with the tested sample on Table 1. A smaller proportion of children were tested in the year 2002-03 than in 2000-01.

The proportion of children with ear problems are given in Table 2. Wax in the

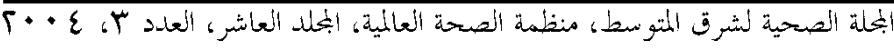




\begin{tabular}{|c|c|c|c|c|}
\hline \multirow[t]{2}{*}{ Variable } & \multicolumn{2}{|c|}{$\begin{array}{c}\text { Study } \\
\text { population }\end{array}$} & \multicolumn{2}{|c|}{$\begin{array}{l}\text { Sample } \\
\text { screened }\end{array}$} \\
\hline & No. & $\%$ & No. & $\%$ \\
\hline \multicolumn{5}{|l|}{ Sex } \\
\hline Male & 2971 & 57.4 & 985 & 52.0 \\
\hline Female & 2202 & 42.6 & 909 & 48.0 \\
\hline \multicolumn{5}{|l|}{ School year } \\
\hline 2000-01 & 1801 & 34.8 & 999 & 52.7 \\
\hline 2001-02 & 1667 & 32.2 & 679 & 35.9 \\
\hline 2002-03 & 1705 & 33.0 & 216 & 11.4 \\
\hline Total & 5173 & 100.0 & 1894 & 100.0 \\
\hline
\end{tabular}

ear canal was present in 64 children $(3.4 \%$, $95 \%$ CI 2.6 to $4.2 \%$ ). Six children had impacted wax, 4 chronic suppurative otitis media and 2 dry perforation of eardrum. In all only 14 children $(0.74 \%, 95 \%$ CI 0.69 to $0.78 \%$ ) had ear problems with hearing impairment. This included 2 children with wax in the ear canal, one with a blood disorder and the other with a history of vertigo with fainting, for whom the health staff were unsure if the origin was an inner ear problem. After repeating the audiometry, all 14 pupils were reconfirmed and referred to the ENT specialist at Salalah Hospital. Only 2 of them attended. If this final outcome is considered in the calculation, the yield of children actually treated for hearing problems was only $0.11 \%$.

Ten doctors and 10 nursing staff spent around 8 to 10 minutes per pupil. Visiting the schools, taking the consent of school authorities, preparing the pupils and area for screening, referring the pupils for further care and following up those with ear problems took another 5 minutes per child. The average salary of a physician is RO 500 and that of a nurse is RO 250. On the basis of a 7-hour day, 20 days a month, the

\begin{tabular}{|c|c|c|}
\hline \multicolumn{3}{|c|}{$\begin{array}{l}\text { Table } 2 \text { Ear conditions and outcomes among } \\
\text { first-year preparatory-school children } \\
\text { screened over } 2000-03 \text { in Oman }\end{array}$} \\
\hline $\begin{array}{l}\text { Ear conditions and } \\
\text { outcomes }\end{array}$ & $\begin{array}{l}\text { No. of } \\
\text { children }\end{array}$ & $\%$ \\
\hline Total screened & 1894 & 100.0 \\
\hline \multicolumn{3}{|l|}{ Minor ear conditions } \\
\hline Wax in ear canal & 64 & 3.38 \\
\hline \multicolumn{3}{|l|}{$\begin{array}{l}\text { Ear conditions with hearing } \\
\text { impairment }\end{array}$} \\
\hline Impacted wax in ear canal & 6 & 0.32 \\
\hline $\begin{array}{l}\text { Chronic suppurative otitis } \\
\text { media }\end{array}$ & 4 & 0.21 \\
\hline Dry eardrum perforation & 2 & 0.11 \\
\hline Otitis media with effusion & 0 & 0 \\
\hline Sensory neural hearing loss & 0 & 0 \\
\hline \multicolumn{3}{|l|}{ Outcome } \\
\hline $\begin{array}{l}\text { Referred to ENT specialist } \\
\text { (Attended specialist) }\end{array}$ & $\begin{array}{l}14^{\mathrm{a}} \\
(2)\end{array}$ & $\begin{array}{l}0.74 \\
(0.11)\end{array}$ \\
\hline
\end{tabular}

$E N T=$ ear, nose and throat.

a2 children with wax in the ear canal were also referred, one with a blood disorder and the other with a history of vertigo with fainting, suspected of having an inner ear problem.

Ministry of Health spends RO 5 per hour as salary to these staff. The salary of physicians and nursing staff for screening each child was thus RO 1.25. The cost of travelling from the primary health care to school for the physician and nurse was RO 0.5 per pupil and the cost of instruments and disposables was RO 0.2 per pupil. The cost per child is therefore RO 1.95 (about US\$ 5). The cost of screening per case with hearing impairment can be calculated as roughly RO 1850 (about US\$4700).

\section{Discussion}

Since 1993, school health staff of the regional directorates in Oman have conducted the annual school health programmes.

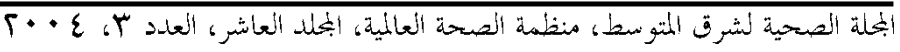


School health was integrated with primary health care in Dhofar region in 1998. In subsequent years, therefore, the health staff managed the schoolchildren of their catchment area in addition to providing health services at primary health centres. Auditory screening of first-year primaryschool children is an ongoing annual activity, but proposals to expand screening to the first-year preparatory level would create additional work that would require more resources. There are many logistic problems if primary care staff are absent from their clinics during morning hours while they undertake health-related activities in schools, especially in small primary health centres with 1 doctor and 2 nursing staff. This emphasizes the importance of the present study to estimate the yield, feasibility and cost-effectiveness of auditory screening of first-year preparatory pupils.

The screening of pupils in school is difficult due to the presence of ambient noise that may affect the quality of screening. To overcome this problem, we used cuffed headphones, ensured pupils' cooperation and supervised the functioning of health staff. Nevertheless, in spite of the efforts of health staff and use of standard techniques, the rate of ear diseases and hearing impairment found at screening was low at $0.74 \%$. The deafness study conducted in 1996 in Oman also suggested a low prevalence of hearing loss and ear diseases among children of Dhofar region [2]. Screening for diseases with low prevalence is known to have a low yield $[5,6]$. The dropout of children identified with hearing problems who did not attend for treatment further reduced the yield of the screening.

As our data covers 3 school years, seasonal epidemics of middle-ear disease are less likely to influence our study results. Conversely, the effectiveness of screening by field staff may have been influenced by the long duration of the study. The data of first-year primary screening of pupils of the same schools by the same staff did not show much variation in the rates of ear diseases and false positive cases in the last 3 years (unpublished school report 2000$03)$.

We could not determine if pupils detected as having a chronic problem through our screening had consulted a primary care physician or ENT specialist at the time of acute symptoms. Generating such information through a separate study could determine the role of screening in identifying a health problem in areas with an established primary care system. If early detection of a health problem could be achieved through an ongoing primary health service that is easily accessible and affordable, the importance of screening pupils in the schools seems to be limited.

In view of the fact that there are a limited number of physicians at primary health centres, that more patients visit health centres during morning hours and that schools are open only in the morning hours means that regular health care in the region would be compromised by deploying staff for additional screening in schools. Using skilled health staff for auditory screening is costly. Hence, many countries screen schoolchildren with the help of paramedical staff or teachers. Such initiatives in Oman could reduce the cost of auditory screening. Use of a questionnaire to identify pupils with a high risk of ear diseases as a first level screening and then conducting audiometric screening and ear examination of these high risk pupils could further increase the yield and reduce the cost of screening. The pupils with conductive deafness and middle ear diseases could easily be managed and hearing loss could be reversed. Many of the chronic conditions found during school screening might have been dealt with in the

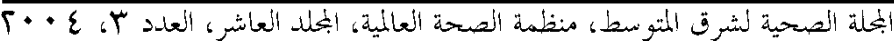


past by health services mainly at primary care centres. In such a situation, screening in schools would duplicate the identification process.

Our study was limited to the wilayat of Dhofar region other than Salalah. The access to health care, level of education of parents and socioeconomic status of children living in Salalah is likely to be better and hence fewer problems are likely to be detected during school screening. Therefore, the cost-effectiveness of screening in Dhofar region would still be low even with the inclusion of Salalah.

In conclusion, our study raised important issues about the rationale for auditory screening of first-year preparatory-school children. Since the prevalence of ear problems in these children is low and the feasibility of using primary health centre staff is low, screening has a low yield and does not seem to be cost-effective. Proposals for introducing auditory screening of firstyear preparatory-school children in Oman should note these factors before making it a national policy. A multi-centred prospective study covering all regions could be conducted for this purpose.

\section{Acknowledgements}

The authors thank the Ministry of Health both at regional and national levels to extend support and encouragement to conduct such epidemiological study. We also appreciate the school health and other staff for undertaking such additional responsibility and maintain high quality of the study. We thank Ms Ruth Mabry and Dr Muluken Malase for their assistance in improving the article.

\section{References}

1. Ear health care manual. Muscat, Oman, Ministry of Health, 1999:11,34.

2. Khabori M, Khandekar R. The prevalence and causes of hearing impairment in Oman-a community based cross sectional study. Journal of audiology (in press).

3. Ministry of Health. General outlines of the health development programmes of the sixth 5-year plan. Muscat, Oman, International Printing Press, 2001:72.
4. Annual health report year 2002. Muscat, Oman, Ministry of Health, 2003:1-8,841.

5. Gordis L, ed. Epidemiology. Philadelphia, USA, WB Saunders, 1996:229-45.

6. Hennekens C, Buring J. Epidemiology in medicine. Boston, USA, Little Brown, 1987:327-45. 